\title{
Prognostic implication of laminin-5 gamma 2 chain expression in the invasive front of colorectal cancers, disclosed by area-specific four-point tissue microarrays
}

\author{
Eiji Shinto ${ }^{1}$, Hitoshi Tsuda ${ }^{1,6}$, Hideki Ueno ${ }^{2}$, Yojiro Hashiguchi ${ }^{2}$, Kazuo Hase $^{3}$,
} Seiichi Tamai ${ }^{4}$, Hidetaka Mochizuki ${ }^{2}$, Johji Inazawa ${ }^{5,6}$ and Osamu Matsubara ${ }^{1}$

${ }^{1}$ Department of Pathology II, National Defense Medical College, Tokorozawa, Japan; ${ }^{2}$ Department of Surgery I, National Defense Medical College, Tokorozawa, Japan; ${ }^{3}$ Department of Surgery, Self Defense Forces Central Hospital, Tokyo, Japan; ${ }^{4}$ Department of Laboratory Medicine, National Defense Medical College, Tokorozawa, Japan; ${ }^{5}$ Department of Molecular Cytogenetics, Medical Research Institute, Tokyo Medical and Dental University, Tokyo, Japan and ${ }^{6}$ Core Research for Evolutional Science and Technology of the Japan Science and Technology Corporation, Kawaguchi, Japan

\begin{abstract}
The laminin-5 gamma 2 chain (LN-5 $\left.\gamma_{2}\right)$ is known to be a marker of invasion in several cancer types. Our purpose was to examine the prognostic significance of $\mathrm{LN}-5 \gamma 2$ expression in different areas of individual colorectal cancers (CRCs) by using tissue microarrays (TMAs), and to clarify the optimal areas for prognostic assessment. Using formalin-fixed paraffin-embedded tissue blocks of pT3 primary CRCs resected from 120 patients, we constructed TMA blocks of tissue core specimens taken from the submucosal invasive front, subserosal invasive front, central area, and rolled edge of each tumor. Using these four-point TMA sets, cytoplasmic LN- $5 \gamma 2$ expression was immunohistochemically surveyed, and the area-specific prognostic significance of $\mathrm{LN}-5 \gamma 2$ expression was evaluated. The data revealed that $35,30,15$ and $10 \%$ of the 120 CRCs showed highgrade LN-5 2 expression in the submucosal invasive front, subserosal invasive front, central area and rolled edge, respectively. Disease-specific survival curves for the groups with high- and low-grade $\mathrm{LN}-5 \gamma 2$ in the submucosal invasive front and subserosal invasive front were different significantly or of marginal difference (respective 5-year survival rates: 54 and $78 \%$ for submucosal invasive front $(P=0.030)$ and 58 and $75 \%$ for subserosal invasive front $(P=0.055))$. Multivariate analysis revealed that the grades of $L N-5 \gamma 2$ expression in submucosal invasive front (hazard ratio $=2.0, P=0.047$ ) and subserosal invasive front (hazard ratio $=2.9$, $P=0.0033$ ) were independent prognostic factors. In contrast, the grades of $\mathrm{LN}-5 \gamma 2$ expression in the central area and rolled edge did not have a significant impact on patient prognosis. Analysis using area-specific fourpoint TMAs clearly demonstrated that $L N-5 \gamma 2$ expression in the invasive front largely influences the degree of clinical aggressiveness of CRC and its tendency to metastasize.
\end{abstract}

Laboratory Investigation (2005) 85, 257-266, advance online publication, 1 November 2004; doi:10.1038/labinvest.3700199

Keywords: area specific; colorectal cancer; four-point; immunohistochemistry; laminin-5 $\gamma 2$ chain; tissue microarray; tumor budding

Colorectal cancer (CRC) is a relatively homogeneous disease from a histological viewpoint, because most primary CRCs are well to moderately differentiated adenocarcinomas showing tubular patterns. However, the manner of spread and metastasis and

Correspondence: Dr H Tsuda, MD, Department of Pathology II, National Defense Medical College, 3-2, Namiki, Tokorozawa, Saitama 359-8513, Japan.

E-mail: htsuda@cc.ndmc.ac.jp

Received 16 April 2004; revised 25 August 2004; accepted

9 September 2004; published online 1 November 2004 patient prognosis vary among individual cases of CRC.

Invasion of cancer cells into their surrounding tissue is an essential step to metastasis. Recently, certain histological features of cancer-cell invasion into surrounding tissues have been shown to be important determinants of clinical behavior of CRC. ${ }^{1,2}$ One such feature is tumor cell dedifferentiation in the invasive front, that is, where cancer cells invade into surrounding tissue at the periphery of a primary tumor. The grade of 'tumor budding', which is the relative number of clusters of 5 or fewer cancer 
cells in the invasive front, has been proposed as a scoring system for tumor cell dedifferentiation, ${ }^{3}$ and correlates with regional and/or distant metastasis and poorer patient prognosis. ${ }^{3-5}$ Furthermore, tumor cell dedifferentiation in primary CRC has been observed not only in the vertical invasive front but also in the lateral invasive front in the submucosal layer. $^{6}$

Although the molecular mechanisms involved in the invasion of CRC are still not completely clear, invasion is known to be correlated with the overexpression of certain molecules. For example, the laminin-5 gamma 2 (LN-5 $\gamma 2)$ chain was recently found to be expressed frequently in the cytoplasm of cancer cells that are invading into surrounding tissue as small clusters. ${ }^{7-9} \mathrm{LN}-5$, which is composed of $\alpha 3, \beta 3$ and $\gamma 2$ chains, is a component of the basement membrane of normal intestinal mucosa. ${ }^{10,11}$ The presence of the $\gamma 2$ chain is a characteristic feature of LN-5, because no other laminins have this chain. ${ }^{12-15}$ An increasing number of reports have demonstrated a correlation between $\mathrm{LN}-5 \gamma 2$ overexpression and clinical behavior of cancers including CRC. ${ }^{16-19}$ However, it is unknown whether the clinical significance of LN-5 $\gamma 2$ expression differs among specific areas within a tumor, for example, the central area, rolled edge, and invasive front.

Tissue microarray (TMA) is a recently developed technique for high-throughput evaluation of protein expression in a large number of archival tissue blocks used for routine histopathological diagnosis. A cohort of tissue core specimens obtained from tissue blocks are arranged into a single recipient paraffin block. ${ }^{20}$ The utility of TMAs has been proved in a number of immunohistochemical studies of various cancer types. ${ }^{21-24}$ However, from the viewpoint of tumor heterogeneity, it is still doubtful whether each tissue core specimen measuring 0.6$2.0 \mathrm{~mm}$ in diameter in a tumor represents the characteristics of the whole tumor.

In the present study, we investigated the prognostic significance of $\mathrm{LN}-5 \gamma 2$ expression in four different specific areas of a CRC, and attempted to clarify the optimal area for prediction of patient prognosis. To complete this trial, we performed immunohistochemistry (IHC) on both a whole tissue section and TMA sections for 120 CRCs at an identical level of local extension (pT3). We examined the area-specific prognostic significance of LN$5 \gamma 2$ expression, and found that the prognosis of patients with pT3 CRC was strongly associated with high-grade LN-5 $\gamma 2$ expression in the submucosal and subserosal invasive fronts, but not in the other two areas examined.

\section{Materials and methods}

\section{Patient Characteristics}

This study was carried out after approval by the internal review board. Among the 613 patients who underwent surgical therapy for primary CRCs at the National Defense Medical College Hospital between 1987 and 1993, we retrieved 120 patients with pT3 CRC, whose tumors had histologically invaded into the subserosal layer or nonperitonealized pericolic or perirectal tissues, according to the TNM classification, 5th edition. ${ }^{25}$ These 120 patients were selected almost consecutively, but they did not include patients for whom there were insufficient data regarding outcome and histopathology, or an insufficient volume of archival paraffin-embedded tissue blocks for TMA construction. Patient characteristics and the clinicopathological features of the CRCs are presented in Table 1.

Features related to 'tumor budding' were divided into two grades, as described previously. ${ }^{3}$ Briefly, we defined the focus of 'tumor budding' as an isolated single cancer cell or a cluster composed of fewer than five cancer cells, then classified cancers as lowgrade if $0-9$ foci were found in a $\times 200$ microscopic field, or high grade if 10 or more foci were found.

Potentially curative surgical procedures, defined as the resection of all macroscopically identifiable tumors, were performed on 104 patients (86.7\%), and palliative surgical procedures on 16 patients $(13.3 \%)$.

All the patients were regularly followed up at our outpatient clinic and monitored for postoperative recurrence using chest X-ray films and measurements of serum carcinoembryonic antigen and carbonhydrate antigen 19-9 levels every 3 months, abdominal ultrasonography every 6 months, and colonoscopy every year. Contrast-enhanced computed tomography was performed when cancer recurrence was suspected. Whenever any findings suggestive of cancer relapse did not appear during 5 years, the follow-up procedure was changed to an annual physical check without any other detailed examinations. If patients did not visit our clinic, we confirmed their health condition by telephone once a year. At the last time of follow-up, 38 patients had died of cancer, with a median interval of 26.3 months (range 1.8-72.7 months) from surgery to death. Overall, 10 patients died of other diseases, with a median interval of 30.9 months (range 1.370.1 months) after surgical treatment. The median follow-up period of the 72 survivors was 79.0 months (range 40.0-135.9 months).

With regard to adjuvant therapies, systemic chemotherapy was performed on only three $(3.0 \%)$ patients who had distant metastasis at the time of initial surgery. No patient free of distant metastasis received systemic chemotherapy in this period. None of the patients received chemotherapy or radiotherapy preoperatively.

\section{Tissue-Microarray Construction}

For each of the 120 cases of CRC, a representative hematoxylin and eosin (HE)-stained section was 
Table 1 Clinicopathological features and their correlations with the grade of LN-5 $\gamma 2$ expression in whole tissue sections of 120 colorectal cancers

\begin{tabular}{|c|c|c|c|c|}
\hline & \multirow[t]{2}{*}{ Total } & \multicolumn{3}{|c|}{ No of cases (\%) } \\
\hline & & $L N-5 \gamma 2$ High grade $(\mathrm{n}=45)$ & $L N-5 \gamma 2$ Low grade $(\mathrm{n}=75)$ & $\mathrm{P}$-value \\
\hline Age, mean \pm s.d. (years) & $60.1 \pm 11.5$ & $62.3 \pm 10.9$ & $58.7 \pm 11.8$ & 0.29 \\
\hline \multicolumn{5}{|l|}{ Sex } \\
\hline Male & 75 & $29(39)$ & 46 & 0.88 \\
\hline Female & 45 & $18(40)$ & 27 & \\
\hline \multicolumn{5}{|l|}{ Primary locus of tumor } \\
\hline Cecum & 9 & $4(44)$ & 5 & 0.87 \\
\hline Ascending colon & 11 & $5(45)$ & 6 & \\
\hline Transverse colon & 9 & $3(33)$ & 6 & \\
\hline Descending colon & 5 & $3(60)$ & 2 & \\
\hline Sigmoid colon & 43 & $15(35)$ & 28 & \\
\hline Rectum & 43 & $15(35)$ & 28 & \\
\hline \multicolumn{5}{|l|}{ Distant metastasis } \\
\hline Positive & 25 & $12(48)$ & 13 & 0.22 \\
\hline Negative & 95 & $33(35)$ & 62 & \\
\hline \multicolumn{5}{|l|}{ Nodal metastasis } \\
\hline Positive & 59 & $28(47)$ & 31 & 0.027 \\
\hline Negative & 61 & $17(28)$ & 44 & \\
\hline \multicolumn{5}{|l|}{ Histological type } \\
\hline Poorly, mucinous & 4 & $2(50)$ & 2 & $0.63^{\mathrm{b}}$ \\
\hline Well, moderately & 116 & $43(37)$ & 73 & \\
\hline \multicolumn{5}{|l|}{ Tumor budding } \\
\hline High grade & 51 & $31(61)$ & 20 & $<0.0001$ \\
\hline Low grade & 69 & $14(20)$ & 55 & \\
\hline \multicolumn{5}{|l|}{ Operation } \\
\hline Potentially curative & 104 & $35(34)$ & 69 & 0.027 \\
\hline Palliative & 16 & $10(63)$ & 6 & \\
\hline
\end{tabular}

${ }^{a}$ Poorly, poorly differentiated adenocarcinoma; mucinous, mucinous adenocarcinoma well; well-differentiated adenocarcinoma; moderately, moderately differentiated adenocarcinoma.

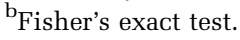

selected by reviewing routine histopathological sections microscopically, and the corresponding tissue blocks stored in the hospital were used for this study. Before construction of the TMA blocks, whole sections were prepared from the 120 representative tissue blocks of CRC for HE staining and IHC. A whole tissue section included both tumor tissue and adjacent normal colorectal mucosal tissue.

In order to construct TMA blocks, a single tissue core was taken from each area of the submucosal invasive front, subserosal invasive front, central area, and rolled edge of a 'donor' block, and the core specimens from approximately 10 CRCs were transferred to a 'recipient' block using a Tissue Microarrayer (Beecher Instruments, Silver Spring, MD, USA) (Figure 1). By referring to a HE-stained whole section, we identified the submucosal invasive front, subserosal invasive front, central area, and rolled edge of the viable tumor tissue in each section, and core specimens of each area were taken from a point in the submucosal invasive front close to the mucosa, a point in the deepest subserosal invasive front, the mid point between the subserosal invasive front and the surface, and one of the highest points of the rolled edge, respectively. We used cores $2.0 \mathrm{~mm}$ in diameter and arranged them $0.7-0.8 \mathrm{~mm}$ apart in a recipient block. One TMA block contained a maximum of 50 tissue cores, and 15 TMA sets, comprising 480 core specimens, were prepared for the present study.

\section{Immunohistochemistry}

Sections, 4- $\mu$ m-thick, were cut from both wholetissue blocks and constructed TMA blocks and mounted on silane-coated glass slides. These sections were deparaffinized with xylene, rehydrated with ethanol and reacted with $5 \%$ hydrogen peroxidase in methanol for 10 min to quench endogenous peroxidase activity. The sections were then treated 


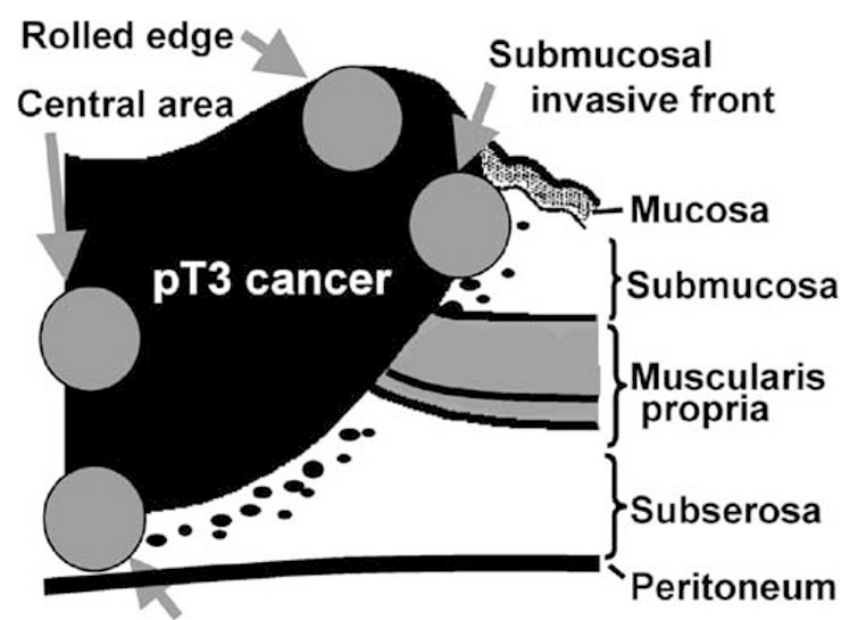

\section{Subserosal invasive front}

Figure 1 Illustration of four areas of a pT3 colorectal carcinoma and sampling sites used for TMA construction in the present study. The right half of the tumor cut surface is presented. The four areas comprise the submucosal invasive front, subserosal invasive front, central area and rolled edge. In the invasive front, 'tumor budding' can occur.

with $0.1 \%$ trypsin (DIFCO, Detroit, MI, USA) for 30 min, incubated in $2 \%$ normal swine serum (Dakocytomation, Grostrup, Denmark) for $10 \mathrm{~min}$ to block nonspecific binding of the antibody, and incubated with mouse monoclonal anti-LN-5 $\gamma 2$ IgG (clone D4B5; dilution 1:200; Chemicon, Temecula, CA, USA) at $4^{\circ} \mathrm{C}$ overnight. Subsequently, the sections were incubated with a secondary antibody covalently linked to dextran polymers containing multiple peroxidase molecules (EnVision System; Dako) for $2 \mathrm{~h}$ at room temperature. For visualization of the antigen, the sections were immersed in $0.05 \%$ diaminobenzidine tetrahydrochloride solution containing $0.01 \%$ hydrogen peroxidase for $8 \mathrm{~min}$, and counterstained lightly with Mayer's hematoxylin.

LN-5 $\gamma 2$ staining in the cytoplasm of cancer cells was regarded as positive immunoreactivity and classified as high- or low-grade. With regard to whole-tissue sections, the grade of $\mathrm{LN}-5 \gamma 2$ staining was evaluated in terms of the percentage of immunopositive cancer cells among the cancer cells at the invasive front. The grade was classified as low if the percentage was less than $20 \%$, and as high if $20 \%$ or more. On the other hand, with regard to the tissue core sections of TMAs, the grade of LN-5 $\gamma 2$ staining was evaluated in terms of the percentage of immunopositive cancer cells among all the cancer cells included, and the grade was classified as low if the percentage was less than $20 \%$, and as high if $20 \%$ or more.

\section{Evaluation of Interobserver Agreement}

Results of IHC staining were evaluated by two observers (ES and HT) independently, and cases with discrepant grades were re-evaluated with discussion. The degree of interobserver agreement for evaluating the LN-5 $\gamma 2$ immunoreaction of wholetissue sections was measured using the generalized $\kappa$ test for two or more observers. ${ }^{26}$ In accordance with the criteria of Landis and Koch, ${ }^{27} \kappa$ values were assigned to a scale of strength of agreement. When the $\kappa$ value was $<0.00,0.00-0.20,0.21-0.40$, $0.41-0.60,0.61-0.80$ and $0.81-1.00$, the strength of agreement was judged as poor, slight, fair, moderate, substantial, and almost perfect, respectively.

\section{Statistical Analysis}

Comparisons between groups were performed using the $\chi^{2}$-test or Fisher's exact method. We used the unpaired $t$-test for comparison of groups with continuous variables following a normal distribution. Survival curves of patients were drawn according to the Kaplan-Meier method. ${ }^{28}$ Differences between curves were calculated using the logrank test. ${ }^{29}$ The Cox proportional hazard model was used for multivariate analysis. ${ }^{30}$ All statistical analyses were performed using Statview 5 software (SAS Institute, Cary, NC, USA) and differences at $P<0.05$ were considered significant.

\section{Results}

Expression Pattern of $\mathrm{LN}-5 \gamma 2$ in Whole-Tissue Sections of CRC

Cytoplasmic LN-5 $\gamma 2$ staining was detected to a variable degree in dedifferentiated carcinoma cells at the invasive front (Figure 2). High-grade LN-5 $\gamma 2$ expression was detected in whole-tissue sections in 45 of 120 CRC cases (37.5\%). The level of interobserver agreement in the evaluation of LN-5 $\gamma 2$ immunostaining was substantial: $87.5 \%(\kappa=0.73)$. In all discrepant cases, agreement was finally reached upon re-evaluation by the two observers using a discussion microscope.

The correlation of LN-5 $\gamma 2$ immunoreactivity with clinicopathological features is shown in Table 1. High-grade LN-5 $\gamma 2$ expression was detected more frequently in the node-metastasis-positive $(28 / 59$, $47.5 \%)$ and high-grade 'tumor budding' (31/51, $60.8 \%$ ) groups than in the node-metastasis-negative $(17 / 61,27.9 \%)(P=0.027)$ and low-grade 'tumor budding' $(14 / 69,20.3 \%)(P<0.0001)$ groups (Figure $2)$. The curativity of surgical procedures for a primary CRC was also correlated with the grade of LN-5 $\gamma 2$ expression $(P=0.027)$. Patient age and sex, histological type and synchronous distant metastasis were not correlated with LN-5 $\gamma 2$ immunoreactivity.

Disease-specific survival curves obviously differed between CRC with high-grade LN-5 22 (5-year survival $46.0 \%$ ) and CRC with low-grade LN-5 $\gamma 2$ (5-year survival $85.0 \%) \quad(P=0.0001) \quad($ Figure 3 ). 

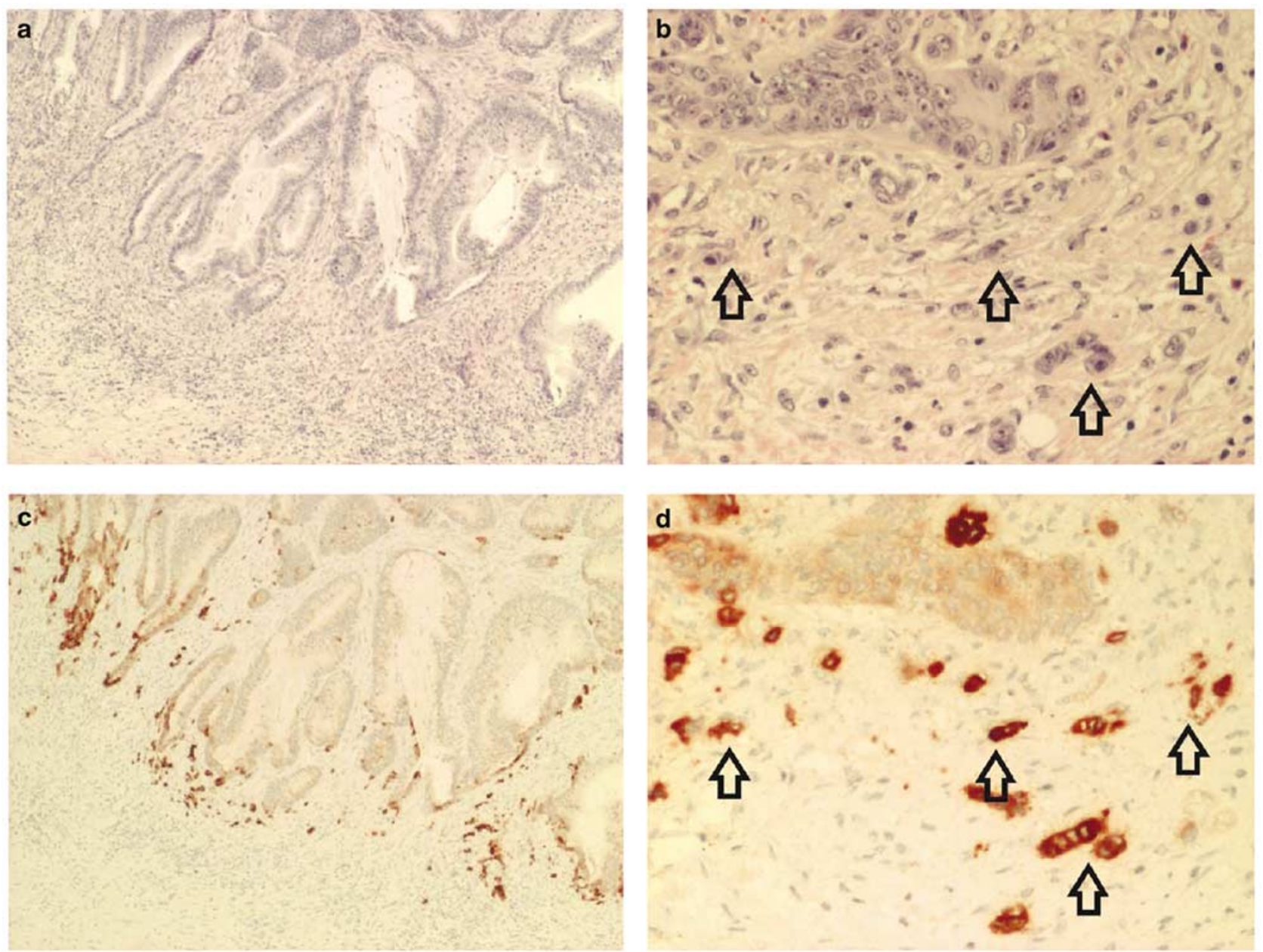

Figure 2 Characteristic microscopic appearance of 'tumor budding' and LN-5 $\gamma 2$ immunostaining in colorectal cancer. (a,b) Histological appearance (HE stain). (a) A low-power view. In the central area of the tumor (upper side), tubular structures are mostly preserved. On the other hand, the foci of 'budding' are located in subserosal invasive front (lower side). (b) A high-power view of the subserosal invasive front. Tumor cell dedifferentiation and a lot of foci of 'tumor budding', which are isolated single cancer cells or clusters of fewer than five cancer cells, are observed (arrows). (c, d) LN-5 $\gamma 2$ immunostaining (immunoperoxidase stain). (c) Same field as (a) LN-5 $\gamma 2$ is expressed zonally in cancer cells constituting the subserosal invasive front. In the central area (upper side), cancer cells are almost negative for the LN-5 $\gamma 2$. (d) Same field as b. LN-5 $\gamma 2$ is strongly positive in the entire cytoplasm of cancer cells in the foci of 'budding' (arrows). (magnifications a, c: $\times 40$ and $\mathbf{b}, \mathbf{d}: \times 200$ ).

Univariate analysis revealed that distant metastasis, nodal metastasis and the grade of 'tumor budding' were also significant prognostic factors $(P<0.0001$ each). Multivariate analysis using Cox's model, including these prognostic indicators as variables, revealed that $\mathrm{LN}-5 \gamma 2$ expression was an independent prognostic factor (hazard ratio 3.5, 95\% confidence interval (CI) $1.8-6.9, P=0.0003$ ), in addition to distant metastasis (hazard ratio 10.9 , 95\% CI 5.322.2, $P<0.0001$ ) and nodal metastasis (hazard ratio $2.3,95 \%$ CI $1.1-5.0, P=0.037$ ) (Table 2). The grade of 'tumor budding' was not included in the multivariate analysis because the grade was strongly correlated with LN-5 $\gamma 2$ expression $(P<0.0001)$.

Among 104 patients who underwent potentially curative surgery, $28(26.9 \%)$ suffered postoperative recurrence. Disease-free survival curves after surgical therapy tended to differ between patients with
CRC showing high-grade LN-5 $\gamma 2$ expression (3-year survival $66.7 \%$ ) and those with CRC showing lowgrade LN-5 $\gamma 2$ expression (3-year survival $81.0 \%$ ), although the difference was not significant $(P=0.067)$.

Of the 28 patients who suffered CRC recurrence, the postrecurrent disease-specific survival rate was significantly lower for the 13 patients whose primary cancers showed high-grade LN-5 $\gamma 2$ (5-year survival $0 \%$ ) than for the 15 patients whose primary cancers showed low-grade LN-5 $\gamma 2$ (5-year survival $34.9 \%)(P=0.0082)$. In this set of patient groups, other clinicopathological parameters of the primary tumors, that is, the presence of distant metastasis or regional lymph node metastasis, did not have a significant influence on postrecurrence patient survival (data not shown). Cox's proportional hazard model including these parameters selected LN-5 $\gamma 2$ 


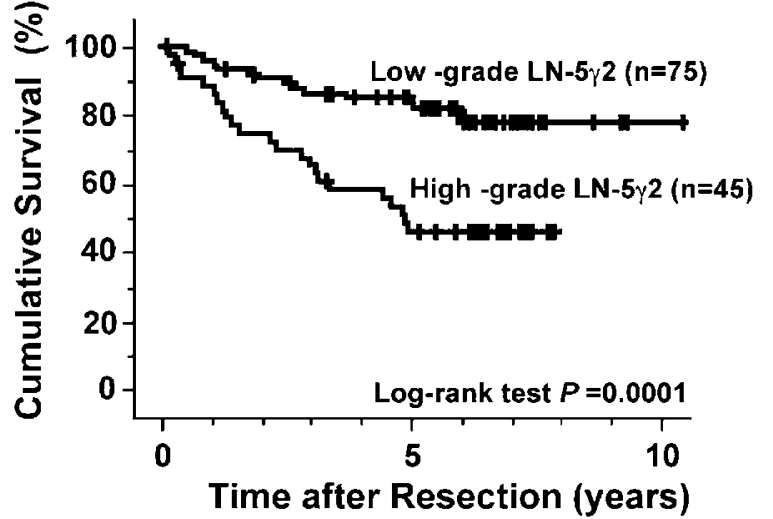

No. of patients

High-grade $\begin{array}{lllllllll}45 & 38 & 32 & 28 & 24 & 19 & 16 & 7 & 0\end{array}$

Low-grade $\begin{array}{llllllllllll}75 & 72 & 66 & 62 & 57 & 53 & 40 & 20 & 6 & 5 & 3\end{array}$

Figure 3 Cumulative disease-specific survival curves for 120 patients with primary colorectal cancers stratified by the grade of LN-5 $\gamma 2$ expression in the analysis of whole-tissue sections. The two curves for patients with high-grade LN-5 $\gamma 2$ expression and low-grade LN-5 $\gamma 2$ expression are significantly different $(P=0.0001)$.

Table 2 Independent significance of clinicopathological parameters for disease-specific survival of 120 patients with colorectal cancer by the Cox's proportional hazard model

\begin{tabular}{lccc}
\hline Parameter & $\begin{array}{c}\text { Hazard } \\
\text { ratio }\end{array}$ & $\begin{array}{c}95 \% \text { Confidence } \\
\text { interval }\end{array}$ & P-value \\
\hline $\begin{array}{l}\text { Distant metastasis } \\
\quad \text { Positive to negative }\end{array}$ & 10.9 & $5.3-22.2$ & $<0.0001^{\mathrm{a}}$ \\
$\begin{array}{l}\text { Nodal metastasis } \\
\quad \text { Positive to negative }\end{array}$ & 2.3 & $1.1-5.0$ & $0.037^{\mathrm{a}}$ \\
$\begin{array}{l}\text { LN-5 } 2 \text { 2 } \\
\text { High- to low grade }\end{array}$ & 3.5 & $1.8-6.9$ & $0.0003^{\mathrm{a}}$ \\
\hline
\end{tabular}

${ }^{\mathrm{a}}$ Statistically significant difference.

expression (hazard ratio 4.6, 95\% CI 1.7-12.3, $P=0.0026$ ) as well as distant metastasis (hazard ratio $3.3,95 \%$ CI $1.2-9.3, P=0.023$ ) as independent postrecurrence prognostic indicators (Table 3 ).

\section{Comparison of Incidence and Prognostic Implication of LN-5 $\gamma 2$ Status among Four Different Sites in Primary CRC Using TMA}

Among tissue core sections from the submucosal invasive front and subserosal invasive front areas, high-grade LN-5 $\gamma 2$ expression was detected in $34.8 \%$ (40 of 115 ) and $30.3 \%$ (36 of 119 ), respectively. On the other hand, among tissue core specimens from the central area and rolled edge areas, high-grade LN-5 $\gamma 2$ expression was detected in only $15.0 \%$ (18 of 120 ) and $10.1 \%$ (12 of 119 ), respectively. The rates of high-grade LN-5 $\gamma 2$ immunostaining differed markedly between the specimens from
Table 3 Independent significance of clinicopathological parameters of primary tumors for postrecurrent disease-specific survival of 28 patients with recurrent colorectal cancer by the Cox's proportional hazard model

\begin{tabular}{lccc}
\hline Parameter & $\begin{array}{c}\text { Hazard } \\
\text { ratio }\end{array}$ & $\begin{array}{c}95 \% \text { confidence } \\
\text { interval }\end{array}$ & P-value \\
\hline $\begin{array}{l}\text { Distant metastasis } \\
\quad \text { Positive to negative }\end{array}$ & 3.3 & $1.2-9.3$ & $0.023^{\mathrm{a}}$ \\
$\begin{array}{c}\text { Nodal metastasis } \\
\quad \text { Positive to negative }\end{array}$ & 1.3 & $0.48-3.3$ & 0.64 \\
$\begin{array}{c}L N-5 \gamma 2 \\
\text { High- to low grade }\end{array}$ & 4.6 & $1.7-12.3$ & $0.0026^{\mathrm{a}}$ \\
\hline
\end{tabular}

${ }^{\mathrm{a}}$ Statistically significant difference.

invasive fronts and the specimens from other areas $(P<0.0001$, submucosal invasive front and subserosal invasive front vs central area and rolled edge). Submucosal invasive front specimens from five CRC cases, a subserosal invasive front specimen from one case and a rolled edge specimen from one case were not informative because of tissue loss or sampling error. The difference in the percentages of highgrade LN-5 $\gamma 2$ among specimens from four different areas of a tumor resulted from the fact that the LN$5 \gamma 2$ was characteristically expressed in the invasive front. Usually, rolled edge and central area specimens did not contain part of the invasive front. If the areas of the rolled edge and central area were relatively small, the tissue cores of central area and rolled edge specimens contained part of the invasive front where LN-5 $\gamma 2$ was usually positive, and such specimens tended to show high-grade LN-5 $\gamma 2$ expression. The grades of $\mathrm{LN}-5 \gamma 2$ expression in tissue core specimens from the submucosal invasive front, subserosal invasive front, central area and rolled edge were concordant with the grade of LN$5 \gamma 2$ expression in the corresponding whole-tissue sections in $70 \%$ (80 of 115), 67\% (80 of 119), $66 \%$ (79 of 120) and $68 \%$ (81 of 119) of cases, respectively. The concordance rate of LN-5 $\gamma 2$ expression grades between submucosal invasive front and subserosal invasive front was $75 \%$ (86 of 114).

The prognostic significance of high-grade LN-5 $\gamma 2$ immunostaining differed markedly between specimens from the invasive front and specimens from other areas. With regard to specimens from the submucosal invasive front and subserosal invasive front, survival curves differed or marginally differed between the high- and low-grade LN-5 $\gamma 2$ groups $(P=0.030$ and 0.055 , respectively), in a similar way to the prognostic results for whole-tissue sections. For specimens from the submucosal invasive front, 5-year survival rates after surgical therapy were 54 and $78 \%$ in the patients with CRC showing highand low-grade LN-5 $\gamma 2$ expression, respectively. For specimens from the subserosal invasive front, the 5year survival rates were 58 and $75 \%$ in these two patient groups, respectively (Figure 4a, b). Cox's 
multivariate analysis revealed the independent significance of $\mathrm{LN}-5 \gamma 2$ status in the submucosal invasive front and subserosal invasive front specimens as a prognostic indicator $(P=0.047$ and 0.0033, respectively) (Table 4).

Furthermore, the grade of $\mathrm{LN}-5 \gamma 2$ expression in the submucosal invasive front specimens was a prognostic indicator in 27 patients with recurrent CRC. Postrecurrent disease-specific survival rate was significantly lower in the eight patients with primary cancers showing high-grade $\mathrm{LN}-5 \gamma 2$ expression (5-year survival 0\%) than in the 19 patients with primary cancers showing low-grade expression (5-year survival $27.2 \%)(P=0.048)$. Cox's propor-

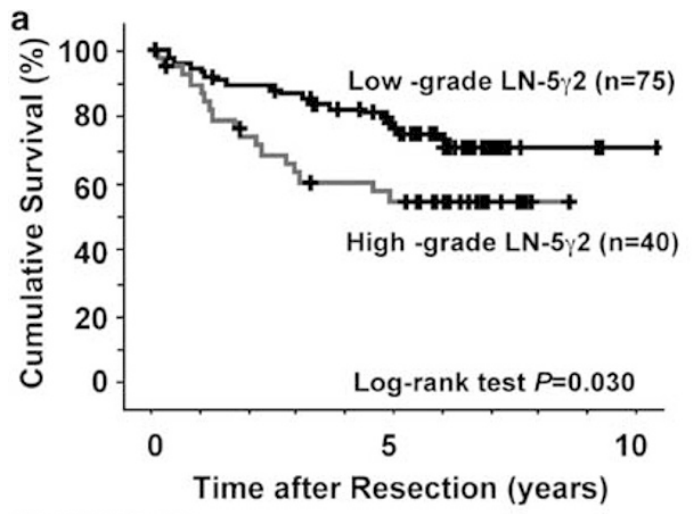

No. of patients

High-grade $\begin{array}{llllllllll}40 & 34 & 27 & 23 & 21 & 19 & 13 & 6 & 1 & 0\end{array}$

Low-grade $\begin{array}{llllllllllll}75 & 71 & 66 & 63 & 56 & 49 & 39 & 18 & 5 & 5 & 3\end{array}$

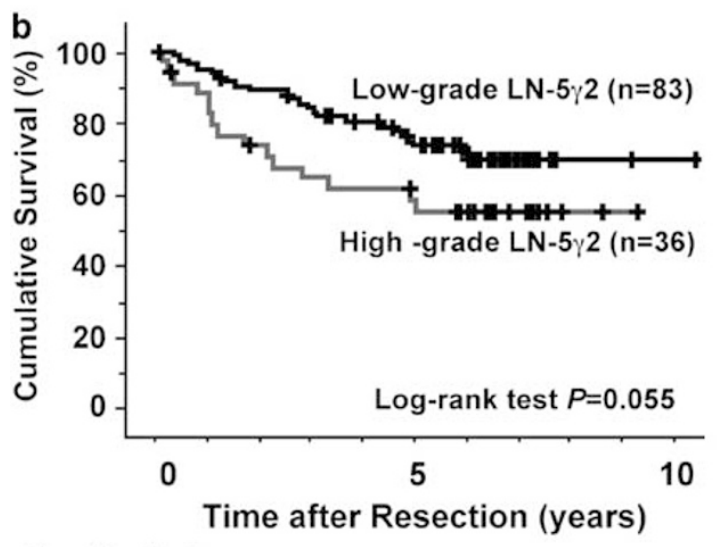

No. of patients

High-grade $\begin{array}{llllllllllll}36 & 30 & 24 & 21 & 20 & 18 & 15 & 9 & 2 & 1 & 0\end{array}$

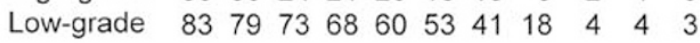

Figure 4 (a) Cumulative disease-specific survival curves for 115 patients with primary colorectal cancer stratified by the grade of $\mathrm{LN}-5 \gamma 2$ expression in the analysis of core specimens from submucosal invasive front in TMA. The two curves for patients with high-grade $\mathrm{LN}-5 \gamma 2$ expression and low-grade $\mathrm{LN}-5 \gamma 2$ expression are significantly different $(P=0.030)$. (b) Cumulative disease-specific survival curves for 119 patients with primary colorectal cancer stratified by the grade of $\mathrm{LN}-5 \gamma 2$ expression in the analysis of core specimens from subserosal invasive front in TMA. The two curves for patients with high-grade LN5- $\gamma 2$ expression and low-grade LN-5 $\gamma 2$ expression tend to be different $(P=0.055)$. tional hazard model selected $\mathrm{LN}-5 \gamma 2$ expression $(P=0.027)$ as an independent postrecurrent prognostic indicator (Table 5). However, the grade of LN$5 \gamma 2$ expression in the subserosal invasive front specimens was not associated with the outcome of patients with recurrent CRC.

In contrast, with regard to specimens from the central area and rolled edge, survival curves did not differ between CRC showing high- and low-grade LN-5 $\gamma 2$ expression ( $P=0.21$ and 0.60 , respectively). For specimens from the central area and rolled edge, 5 -year survival rates after surgical therapy were 57 and $64 \%$ in the patients with high-grade LN-5 $\gamma 2$ expression, compared with 72 and $72 \%$ in the patients with low-grade $\mathrm{LN}-5 \gamma 2$ expression, respectively. Multivariate analysis revealed no independent significance of $\mathrm{LN}-5 \gamma 2$ status in the central area and rolled edge specimens as a prognostic indicator $(P=0.25$ and 0.70 , respectively) .

Table 4 Independent significance of the grade of $\mathrm{LN}-5 \gamma 2$ expression in submucosal invasive front and subserosal invasive front areas for disease-specific survival of 120 patients with colorectal cancer by the Cox's proportional hazard model

\begin{tabular}{lcccc}
\hline Parameter & $\begin{array}{c}\text { TMA taken from } \\
\text { submucosal } \\
\text { invasive front }\end{array}$ & $\begin{array}{c}\text { TMA taken from } \\
\text { subserosal invasive } \\
\text { front }\end{array}$ \\
\cline { 2 - 5 } & $\begin{array}{c}\text { Hazard } \\
\text { ratio }\end{array}$ & P-value & $\begin{array}{c}\text { Hazard } \\
\text { ratio }\end{array}$ & P-value \\
\hline $\begin{array}{c}\text { Distant metastasis } \\
\text { Positive to negative }\end{array}$ & 10.9 & $<0.0001^{\mathrm{a}}$ & 10.6 & $<0.0001^{\mathrm{a}}$ \\
$\begin{array}{c}\text { Nodal metastasis } \\
\text { Positive to negative }\end{array}$ & 2.8 & $0.011^{\mathrm{a}}$ & 2.6 & $0.021^{\mathrm{a}}$ \\
$\begin{array}{c}\text { LN-5 } 2 \\
\text { High- to low grade }\end{array}$ & 2.0 & $0.047^{\mathrm{a}}$ & 2.9 & $0.0033^{\mathrm{a}}$ \\
\hline
\end{tabular}

${ }^{\mathrm{a}}$ Statistically significant difference.

Table 5 Independent significance of the grade of LN-5 $\gamma 2$ expression in submucosal invasive front and subserosal invasive front areas for post-recurrent disease-specific survival of 28 patients with recurrent colorectal cancer by the Cox's proportional hazard model

\begin{tabular}{lcccc}
\hline Parameter & $\begin{array}{c}\text { TMA taken from } \\
\text { submucosal } \\
\text { invasive front }\end{array}$ & $\begin{array}{c}\text { TMA taken from } \\
\text { subserosal invasive } \\
\text { front }\end{array}$ \\
\cline { 2 - 5 } & $\begin{array}{c}\text { Hazard } \\
\text { ratio }\end{array}$ & P-value & $\begin{array}{c}\text { Hazard } \\
\text { ratio }\end{array}$ & P-value \\
\hline $\begin{array}{c}\text { Distant metastasis } \\
\text { Positive to negative }\end{array}$ & 2.4 & 0.085 & 2.2 & 0.11 \\
$\begin{array}{c}\text { Nodal metastasis } \\
\text { Positive to negative }\end{array}$ & 1.2 & 0.77 & 0.99 & 0.98 \\
$\begin{array}{c}\text { LN-5 } 2 \\
\text { High- to low grade }\end{array}$ & 2.9 & $0.027^{\mathrm{a}}$ & 1.6 & 0.34 \\
\hline
\end{tabular}

${ }^{\mathrm{a}}$ Statistically significant difference. 


\section{Discussion}

In the present study, we immunohistochemically examined LN-5 $\gamma 2$ expression in surgically resected CRCs showing the same extent of local spread, that is, pT3. Using whole-tissue sections, Lenander et $a l^{18}$ and Aoki et $a l^{19}$ showed that LN-5 $\gamma 2$ expression was correlated with an unfavorable outcome in patients with CRC. Using both univariate and multivariate analyses, we also demonstrated that the grade of LN-5 $\gamma 2$ expression had a great effect on patient outcome. Furthermore, we found that high-grade LN-5 $\gamma 2$ expression in primary CRCs was an independent postrecurrence prognostic indicator. These novel findings may be clinically applicable for patient follow-up after resection of primary tumors and for choosing adjuvant therapies or postrecurrent therapies.

In addition, by means of TMA devised to reveal the significance of $\mathrm{LN}-5 \gamma 2$ expression in different areas of a tumor, we clearly demonstrated intratumoral heterogeneity of $\mathrm{LN}-5 \gamma 2$ expression with regard to both positivity rate and prognostic implication. High-grade $\mathrm{LN}-5 \gamma 2$ expression was detected more frequently in specimens taken from the submucosal invasive front and subserosal invasive front than in those taken from the rolled edge and central area. The grades of LN-5 $\gamma 2$ expression in the submucosal invasive front and subserosal invasive front were significantly correlated with patient outcome, whereas those in the rolled edge and central area were not.

In the present study, by employing TMA, we actually verified that dedifferentiated cancer cells in tissue cores from the invasive front, both the vertical invasive front in the subserosal layer and the lateral invasive front in the subserosal layer, showed overexpression of $\mathrm{LN}-5 \gamma 2$, and confirmed that the grade of LN-5 $\gamma 2$ expression in the invasive front was of prognostic significance in patients with primary CRCs. Additionally, such overexpression in submucosal invasive front specimens had a prognostic influence in patients with recurrent CRC. In contrast, high-grade LN-5 $\gamma 2$ expression in tissue core specimens from the central area and rolled edge was less frequent and had no prognostic significance. Consequently, we clearly demonstrated that high-grade LN-5 $\gamma 2$ expression in dedifferentiated cells at the invasive front largely influenced the clinical aggressiveness of CRC and its potential to metastasize.

It is well recognized that TMA is efficient for screening of molecular alterations in a large number of tumor cases. In contrast, major drawback proper to TMA analysis consists in that the characteristics of sampled tissue do not always represent those of whole tumor. However, in this study, we showed that LN-5 $\gamma 2$ expression in invasive fronts, but not in central area or rolled edge, correlated with clinical aggressiveness. Therefore, area-specific TMA was concluded to be effective not only for high-throughput screening of molecular alterations but also for the identification of prognostic factors in CRC, at an approximately similar level with whole-tissue section analysis.

Abnormally strong expression of the LN-5 $\gamma 2$ has been characteristically detected by IHC in dedifferentiated cells dissociated from the neoplastic tubules of CRCs in whole-tissue sections, ${ }^{7,8}$ and a tight correlation between the grade of LN-5 $\gamma 2$ expression and tumor dedifferentiation has been proved. ${ }^{18,31}$ These pathological findings were supported by recent molecular studies which revealed that the cleavage of LN-5 chains by membrane-type 1 matrix metalloproteinase induced epithelial migration, ${ }^{32}$ and that both LN-5 $\gamma 2$-coding gene and membranetype matrix metalloproteinase gene were targets of the Wnt- $\beta$-catenin-T-cell factor signaling. ${ }^{33-35} \mathrm{In}$ Hlubek's studies, nuclear $\beta$-catenin accumulation, which was detected at the invasive front of CRC, enhanced transactivation of these two genes. ${ }^{34,35}$ It is conceivable that the Wnt- $\beta$-catenin-T-cell factor signaling pathway triggers the enhancement of cancer cell motility and invasion through the interaction with these two molecules.

In the present study, we confirmed that the grade of LN-5 $\gamma 2$ was highly correlated with the grade of 'tumor budding', which is a morphological index of tumor dedifferentiation at the invasive front of primary CRCs, and with patient prognosis in primary CRC and recurrent CRC. The grade of 'tumor budding' has also been shown to be a powerful prognostic factor for patients with postoperative liver recurrence as well as patients with primary CRC. ${ }^{36}$ Because of our favorable interobserver agreement for the judgment of LN-5 $\gamma 2$ expression, its evaluation was indicated to be useful as an objective marker of tumor cell dedifferentiation at the invasive front of CRC in a clinicopathological setting.

TMA may be useful for investigating the incidence and clinical significance of the expression of multiple different molecules in a large number of tumor cases, and the validity of TMA analysis has been reported to be acceptable. ${ }^{21,23}$ However, previous studies did not emphasize the importance of taking tissue core samples from specific areas in the tumor. In CRC, Chung et $a l^{37}$ and Hoos et $a l^{38}$ employed TMA for the detection of $\beta$-catenin, phospho- $\beta$-catenin, p53, mdm-2, p21, Bcl-2, p27, cyclin D1 and Ki-67, but in those studies, the sites from which the tumor tissue core specimens were sampled were not rigorously specified. They showed that only the levels of phospho- $\beta$-catenin and p27 were associated with survival rate, although the alterations of these eight molecules had already been shown to be prognostic factors by other investigators.

Other than LN-5 $\gamma 2$, a number of proteins have been reported to show a difference in expression pattern between the invasive front and other areas in individual primary CRCs. These proteins comprise proliferating cell nuclear antigen, ${ }^{39,40} \mathrm{CEA},{ }^{41} \mathrm{NF}$ - 
kappa $\mathrm{B},{ }^{42}$ matrilysin ${ }^{43}$ and trypsin. ${ }^{44}$ The expression level of these proteins in the invasive front was shown to predict the malignant potential of CRC. Therefore, the area-specific multiple sampling method employed for the construction of TMAs in the present study seemed particularly applicable for analyzing the clinical and histopathological significance of molecules associated with cancer invasion and metastasis. Furthermore, we suggested that sampling of tissues from parts of the invasive front would be essential for TMA analysis of CRCs, irrespective of the volume of the invasive front.

A majority of TMA examinations have adopted a 0.6-mm-diameter punch in order to achieve highthroughput potential. ${ }^{20-24}$ However, we preferred a 2.0-mm-diameter punch in order to obtain tissue core samples that would be guaranteed to contain the areas of the invasive front. In fact, the line of the invasive margin often showed a shift of approximately $0.5 \mathrm{~mm}$ from the core center, because of the accumulation of delicate shifts resulting from the manual punch and/or an unexpected tumor-margin shift due to tissue loss during section preparation. From such experience, we considered that a 0.6mm-diameter punch would often fail to sample the areas of the invasive front that we intended to obtain. In 115 of 120 specimens from the submucosal invasive front and in 119 of 120 specimens from the subserosal invasive front in the present cohort, 2-mm-diameter tissue cores contained discrete samples of the invasive front with surrounding normal connective tissue. Therefore, we believe that a 2.0mm-diameter punch is a more appropriate procedure for TMA in studies of the CRC invasive front.

In conclusion, we have found that the grade of $\mathrm{LN}-5 \gamma 2$ expression in whole-tissue sections is strongly correlated with the prognosis of patients with primary CRC and that of patients with recurrent CRC. Moreover, the present TMA analysis has revealed that $\mathrm{LN}-5 \gamma 2$ expression in samples taken from the invasive front in both the submucosal and subserosal layers is an independent prognostic factor of CRC. This is the first report to emphasize the importance of constructing area-specific multipoint TMAs for the study of CRC.

\section{Acknowledgements}

Supported in part by Grants-in-Aid from the Foundation for the Promotion of Cancer Research, Japan, the Chugai Pharmaceutical Co., Japan, the Fujisawa Pharmaceutical Co., Japan and the Taiho Pharmaceutical Co., Japan.

\section{References}

1 Jass JR, Love SB, Northover JMA. A new prognostic classification of rectal cancer. Lancet 1987;6: 1303-1306.
2 Ono M, Sakamoto M, Ino $\mathrm{Y}$, et al. Cancer cell morphology at the invasive front and expression of cell adhesion-related carbohydrate in the primary lesion of patients with colorectal carcinoma with liver metastasis. Cancer 1996;78:1179-1186.

3 Ueno H, Murphy J, Jass JR, et al. Tumour 'budding' as an index to estimate the potential of aggressiveness in rectal cancer. Histopathology 2002;40:127-132.

4 Hase K, Shatney C, Johnson D, et al. Prognostic value of tumor 'budding' in patients with colorectal cancer. Dis Colon Rectum 1993;36:627-635.

5 Tanaka M, Hashiguchi Y, Ueno H, et al. Tumor budding at the invasive margin can predict patients at high risk of recurrence after curative surgery for stage II, T3 colon cancer. Dis Colon Rectum 2003;46:1054-1059.

6 Ueno H, Mochizuki H, Shinto E, et al. Histologic indices in biopsy specimens for estimating the probability of extended local spread in patients with rectal carcinoma. Cancer 2002;94:2882-2891.

7 Pyke C, Romer J, Kallunki P, et al. The 2 chain of kalinin/laminin 5 is preferentially expressed in invading malignant cells in human cancers. Am J Pathol 1994;145:782-791.

8 Sordat I, Bosman FT, Dorta G, et al. Differential expression of laminin-5 subunits and integrin receptors in human colorectal neoplasia. J Pathol 1998; 185:44-52.

9 Pyke C, Salo S, Ralfkiaer E, et al. Laminin-5 is a marker of invading cancer cells in some human carcinomas and is coexpressed with the receptor for urokinase plasminogen activator in budding cancer cells in colon adenocarcinomas. Cancer Res 1995;55:4132-4139.

10 Simon-Assmann P, Kedinger M. Heterotypic cellular cooperation in gut morphogenesis and differentiation. Semin Cell Biol 1993;4:221-230.

11 Mizushima H, Koshikawa N, Moriyama K, et al. Wide distribution of laminin-5 gamma 2 chain in basement membranes of various human tissues. Horm Res 1998;50(Suppl 2):7-14.

12 Kallunki P, Sainio K, Eddy R, et al. A truncated laminin chain homologous to the B2 chain: structure, spatial expression, and chromosomal assignment. J Cell Biol 1992;119:679-693.

13 Rousselle P, Lunstrum GP, Keene DR, et al. Kalinin: an epithelium-specific basement membrane adhesion molecule that is a component of anchoring filaments. J Cell Biol 1991;114:567-576.

14 Gerecke DR, Wagman DW, Champliaud MF, et al. The complete primary structure for a novel laminin chain, the laminin B1k chain. J Biol Chem 1994;269: 11073-11080.

15 Ryan MC, Tizard R, VanDevanter DR, et al. Cloning of the LamA3 gene encoding the alpha 3 chain of the adhesive ligand epiligrin. Expression in wound repair. J Biol Chem 1994;269:22779-22787.

16 Baker SE, DiPasquale AP, Stock EL, et al. Morphogenetic effects of soluble laminin-5 on cultured epithelial cells and tissue explants. Exp Cell Res 1996;228: 262-270.

17 Koshikawa N, Moriyama K, Takamura H, et al. Overexpression of laminin gamma2 chain monomer in invading gastric carcinoma cells. Cancer Res 1999;59: 5596-5601.

18 Lenander C, Habermann JK, Ost A, et al. Laminin-5 gamma 2 chain expression correlates with unfavorable prognosis in colon carcinomas. Anal Cell Pathol 2001;22:201-209. 
19 Aoki S, Nakanishi Y, Akimoto S, et al. Prognostic significance of laminin-5 gamma2 chain expression in colorectal carcinoma: immunohistochemical analysis of 103 cases. Dis Colon Rectum 2002;45: 1520-1527.

20 Kononen J, Bubendorf L, Kallioniemi A, et al. Tissue microarrays for high-throughput molecular profiling of tumor specimens. Nat Med 1998;4:844-847.

21 Camp RL, Charette LA, Rimm DL. Validation of tissue microarray technology in breast carcinoma. Lab Invest 2000;80:1943-1949.

22 Torhorst J, Bucher C, Kononen J, et al. Tissue microarrays for rapid linking of molecular changes to clinical endpoints. Am J Pathol 2001;159:22492256.

23 Hoos A, Urist MJ, Stojadinovic A, et al. Validation of tissue microarrays for immunohistochemical profiling of cancer specimens using the example of human fibroblastic tumors. Am J Pathol 2001;158:1245-1251.

24 Hendriks Y, Franken P, Dierssen JW, et al. Conventional and tissue microarray immunohistochemical expression analysis of mismatch repair in hereditary colorectal tumors. Am J Pathol 2003;162:469-477.

25 Sobin LH, Wittekind CH (eds). UICC TNM Classification of Malignant Tumors, 5th edn. Wiley-Liss: New York, 1997.

26 Fleiss JL. Measuring nominal scale agreement among many raters. Psychol Bull 1971;76:378-382.

27 Landis JR, Koch GG. The measurement of observer agreement for categorical data. Biometrics 1977;33: 159-174.

28 Kaplan E, Meier P. Nonparametric estimation from incomplete observations. J Am Stat Assoc 1958;53: 457-481.

29 Mantel N. Evaluation of surgical data and two new rank order statistics arising in its consideration. Cancer 1966;50:163-170.

30 Cox DR. Regression models and life-tables. J Royal Stat Soc Series B 1972;34:187-220.

31 Masaki T, Matsuoka H, Sugiyama M, et al. Laminin-5 gamma2 chain expression as a possible determinant of tumor aggressiveness in $\mathrm{T} 1$ colorectal carcinomas. Dig Dis Sci 2003;48:272-278.

32 Koshikawa N, Giannelli G, Cirulli V, et al. Role of cell surface metalloprotease MT1-MMP in epithelial cell migration over laminin-5. J Cell Biol 2000;148: $615-624$.
33 Takahashi M, Tsunoda T, Seiki M, et al. Identification of membrane-type matrix metalloproteinase- 1 as a target of the beta-catenin/Tcf4 complex in human colorectal cancers. Oncogene 2002;21:5861-5867.

34 Hlubek F, Jung A, Kotzor N, et al. Expression of the invasion factor laminin gamma2 in colorectal carcinomas is regulated by beta-catenin. Cancer Res 2001; 61:8089-8093.

35 Hlubek F, Spaderna S, Jung A, et al. Beta-catenin activates a coordinated expression of the proinvasive factors laminin-5 gamma2 chain and MT1-MMP in colorectal carcinomas. Int J Cancer 2004;108:321-326.

36 Ueno H, Mochizuki H, Hatsuse K, et al. Indicators for treatment strategies of colorectal liver metastases. Ann Surg 2000;231:59-66.

37 Chung GG, Provost E, Kielhorn EP, et al. Tissue microarray analysis of beta-catenin in colorectal cancer shows nuclear phospho-beta-catenin is associated with a better prognosis. Clin Cancer Res 2001;7: 4013-4020.

38 Hoos A, Nissan A, Stojadinovic A, et al. Tissue microarray molecular profiling of early, node-negative adenocarcinoma of the rectum: a comprehensive analysis. Clin Cancer Res 2002;8:3841-3849.

39 Teixeira CR, Tanaka S, Haruma K, et al. Proliferating cell nuclear antigen expression at the invasive tumor margin predicts malignant potential of colorectal carcinomas. Cancer 1994;73:575-579.

40 Choi HJ, Jung IK, Kim SS, et al. Proliferating cell nuclear antigen expression and its relationship to malignancy potential in invasive colorectal carcinomas. Dis Colon Rectum 1997;40:51-59.

41 Teixeira CR, Tanaka S, Haruma K, et al. Carcinoembryonic antigen staining patterns at the invasive tumor margin predict the malignant potential of colorectal carcinoma. Oncology 1994;51:228-233.

42 Evertsson S, Sun XF. Protein expression of NF-kappaB in human colorectal adenocarcinoma. Int J Mol Med 2002;10:547-550.

43 Adachi Y, Yamamoto H, Itoh F, et al. Clinicopathologic and prognostic significance of matrilysin expression at the invasive front in human colorectal cancers. Int J Cancer 2001;95:290-294.

44 Yamamoto H, Iku S, Adachi Y, et al. Association of trypsin expression with tumour progression and matrilysin expression in human colorectal cancer. J Pathol 2003;199:176-184. 